\title{
KNOWLEDGE ACQUISITION CAPABILITY, STRATEGIC RESPONSE CAPABILITY, AND ORGANIZATIONAL PERFORMANCE: A MEDIATION ANALYSIS
}

\author{
Onamusi Abiodun Babatunde \\ Department of Management \& Accounting, Lead City University, Ibadan, Oyo State, Nigeria \\ abiodunonamusi@gmail.com
}

\begin{abstract}
This study examined the effect of knowledge acquisition capability on organizational performance of firms in multiple industries in Oyo State, Nigeria, more so, it investigated the indirect effect of strategic response capability on the interaction between knowledge acquisition capability and organizational performance. The cross-sectional survey is designed with a sample of 343 employees from multiple industries; including banks, insurance, FMCGs, telecoms and small and medium enterprises in Oyo State, Nigeria. The multiple regression analysis to test the mediation hypotheses was conducted. The results show that knowledge acquisition capability has a positive and significant effect on organizational performance $\left(R^{2}=0.306, F(1,341)=150.057, \beta=0.489, t=12.250, p=0.000\right)$,). Further analysis shows that when strategic response capability was incorporated into the model as a multiple regression analysis, (Adj. $\left.R^{2}=0.462, F(2,340)=148.135 p=0.000\right)$ reveals that while the coefficient of strategic response capability had significant effect $(\beta=0.732, t=10.092, p=0.000)$ on organizational performance, the coefficient of knowledge acquisition capability became insignificant $(\beta=-0.084, t=-1.262, p=0.208)$ suggesting that a full mediation effect was established. The findings suggest that knowledge acquisition capability benefit organizational performance through the deployment of strategic response capability. Therefore, the study recommended that firms should strengthen their competency to develop innovative means of acquiring knowledge either from within or outside the organization, more so they should develop highly creative means to respond to both competitive rivalry and environmental challenges. This is because both capabilities can be adopted as competitive strategies in responding to changing environment and achieving significant superior performance.

Keywords: Dynamic capability theory, Knowledge acquisition capability, Multi-industry analysis, Performance, Strategic response capability
\end{abstract}

\section{INTRODUCTION}

The ripple effects of the rampaging COVID-19 pandemic on business survival and prosperity suggest that organizations need to renew their firm-level resources and competencies to be able to operate within the restrictions of this pandemic. To achieve this renewable of capabilities, the knowledge-based perspective stressed that knowledge is a critical resource for organizations and the ability to create, renew, recombine, and take advantage of knowledge as resources is crucial for achieving radical 
innovation and sustain competitive advantage in a changing environment (Grant, 1996; Szulanski et al., 2016; Xie et al., 2018). Based on business environment literature, a firm can better control and manage its internal resources (including knowledge) to achieve set goals: financial, market/operational, and overall performance. Achieving the set goals is not an easy task because a firm does not operate in isolation; rather it operates within a vast, dynamic, and turbulent environment.

As a result, a firm needs external knowledge to enhance internal resources in achieving its performance and survival. To achieve this, firms need to develop the capability to identify, assess, and obtain external knowledge considered germane to its business activities (Chen et al., 2016; Forés and Camisón, 2015; Kavusan et al., 2016). Extant literature has shown that such external knowledge can be acquired from informal-unregistered-firms (McCann and Bahl, 2016), competitive intensity (Feng et al., 2018), collaborative-relationship (Najafi-Tavani et al., 2018), supplier integration (Vanpoucke et al., 2014), market (Mu, 2015; Mu et al., 2018), local-relationship (Zhang and Hartley, 2018), customers (Fidel et al., 2015), and capabilities to influence government (Chen et al., 2016).

Although empirical studies have been done on knowledge acquisition capability and its attendant consequences on organizational performance in developed economies and emerging markets (Forés, and Camisón, 2016; Frankort, 2016; Kavusan et al., 2016; Garcia Martinez et al., 2018; Segarra-Ciprés and Bou-Llusar, 2018; Segarra-Ciprés et al., 2014; Xie et al., 2018), however, these studies did not consider the mediating effect of strategic response capability on the interaction between knowledge acquisition capability and organizational performance. The consequence of the gap limits our knowledge of the significant contribution of knowledge acquisition capability to organizational performance. More so, it has limited our comprehensive perspective of the relevance of strategic response capability and more importantly, under what condition will the link between knowledge acquisition capability and organizational performance be explained. This study argues that firms that possess the capability to acquire knowledge from the external environment that is critical to the firm's internal operations would enhance the firms' ability to respond to market dynamics and competitive intensity than those who do not. More so, if such firms' can effectively develop a strategic response capability, it would mediate the interaction between knowledge acquisition capability and organizational performance.

\section{LITERATURE REVIEW}

\subsection{Theoretical Framework and Hypotheses Development}

This study adopts the dynamic capability theory (DCT) to validate the effect of KAC on organizational performance focusing on multiple industries in Oyo State, Nigeria, and to ascertain the mediating effect 
of SRC on the functional relationship between KAC and organizational performance. The dynamic capability theory offered precise implications for this study. The central idea of the DCT, suggest that achieving superior performance in a fast-changing environment is a function of possessing the competency and the ability to integrate, develop peculiar internal and external competences, and constantly reconfigure these competencies to accommodate these changes (Chukwuemeka and Onuoha, 2018; Kaur and Mehta, 2017). The proponents of the DCT opined by the above narrative that there is a direct and indirect interaction between the ownership of dynamic internal-external capabilities and superior performance (Lee et al., 2016). In this regard, the DCT was able to provide a theoretical explanation for the interaction between KAC, SRC, and organizational performance and the hypotheses formulated. Specifically, DCT has been an outside-in and inside-out perspective that suggests that organizations desirous of sustaining competitive advantage must develop and deploy renewable internal and external competencies that are considered unique.

On the strength of the foregoing, the study argues that considering KAC is a capability that can be consistently reconfigured to meet environmental dynamics, a firm that displays this competency would achieve superior performance. More so, the interactionist perspective of fit-as-mediator suggests that when the indirect effect between two variables is explained by a third, then a mediation effect is achieved. Given the foregoing, this study proposed that: (H1) Firms who possess the capability to acquire critical business knowledge (KAC) will experience a significant effect on organizational performance. More so, $(\mathrm{H} 2)$ the interaction term of KAC and SRC would mediate the functionrelationship between KAC and organizational performance.

\subsection{EMPIRICAL REVIEW}

\subsubsection{Knowledge Acquisition Capability and Organizational Performance}

In an attempt to substantiate the interaction between external knowledge acquisition, internal knowledge transfer, and innovation performance, Segarra-Ciprés et al., (2014) demonstrated that the alignment of internal knowledge transfer and external knowledge acquisition enhance organizational performance in innovation. Besides, Segarra-Ciprés et al. (2014) emphasized that the contribution of knowledge alignment to the innovation process depends to a large extent on a work environment that allows employees to share and assess knowledge through a formal coordination and communication system within the organization.

In a related study on the relevance of KAC to product innovation performance, Liao and Marsillac (2015) suggested that organization with strong organizational awareness enables knowledge acquisition capability to interact with supply capability to significantly influence performance. By this study, Liao and 
Marsillac (2015) responded to the call for publication on "the exploration of mechanisms that facilitate the transformation of knowledge from outside a firm into internal-firm innovation performance". Although Liao and Marsillac (2015) share similarities with Segarra et al. (2014) concerning knowledge acquisition and innovation performance, the moderating variables examined in both studies differ. While Segarra et al. (2014) considered internal knowledge transfer, Liao and Marsillac (2015) examined organizational awareness, supply chain network-oriented flexibility. Nevertheless, both studies upheld the underlining significance of knowledge acquisition to organizational performance.

In a similar study to Liao and Marsillac (2015) and Segarra-Cipres et al. (2014), Frankort (2016) was interested in providing an empirical response to the question: "when does knowledge acquisition in R\&D alliances increase new product development?". Frankort's (2016) study established that where a firm acquires higher technical knowledge via strategic alliance in research and development, such a firm is highly likely to achieve better new product development performance. Further analysis showed that knowledge acquisition had significant contributions to the firms' new product development activities in the strategic alliance activities. Much like Frankort (2016), Forés and Camisón (2016) study revealed that the combined interaction of internal knowledge creation capability and absorptive capability explained a positive and significant effect on incremental innovation performance. However, this positive significant contribution to innovation performance is preconditioned on organizations that can fit their internal knowledge base with their external knowledge sources.

Also, Xie et al. (2018) study revealed that inter-organizational knowledge acquisition has a significant positive impact on firms' radical innovation performance; more so, that absorptive capacity possesses an indirect effect on the interaction between inter-firm knowledge acquisition and firms' radical innovation. A study that corroborated Frankort (2016) and Forés and Camisón (2016) about how best to achieve significant performance effects of knowledge acquisition capability were Segarra-Ciprés and Bou-Llusar (2018). The scholars suggested that firms that exhibit ambidextrous search for knowledge from the external environment stand to achieve higher innovation performance. In addition, the innovation performance attributable to knowledge search is premised on the firm innovation activities and the features of the technological routine in operation in the industry where the firm functions.

On what leads to business failures and on how firms can survive its attendant negative consequences, Garcia-Martinez et al. (2018) posited that financial crisis usually escalates the likelihood of business failure. Nevertheless, firms that deploy the capability to cooperate with vertical business partners (customers and suppliers) and acquire knowledge in the course of the interaction are highly likely to secure superior performance hence reducing the effect of business failure in the context of the 
manufacturing industry. By their implication and capability to acquire knowledge presents firms with a rare opportunity to survival a turbulent environment bedeviled by the financial crisis.

\subsubsection{The Mediating Effect of Strategic Response Capability}

Possessing the capability to acquire knowledge is a critical precondition for organizational performance as established in extant literature (Arokodare, 2020; Muchiri et al., 2017; Imalingat, 2015). However, more can be achieved through developing strategic response capability to deploy the knowledge acquired from within and outside the organization. Hence, with regards to the moderating effect of strategic response capability, on the effect of knowledge acquisition capability on organization performance, not much has been done in this direction to position the interaction. Majority of the studies on strategic response capability focused more on how it aids the performance of several organizations in a turbulent environment in different contexts: Oil and gas industry (Arokodare, 2020; Muchiri et al., 2017); Banking industry (Imalingat, 2015); Textile industry (Ketchen and Palmer, (2013); agrochemical industry (Kimunguyi, 2013); manufacturing industry (Collins, 2014); service industry (Akinyele and Fasogbon, 2010). Considering none of these studies addressed the link between strategic response capability, knowledge acquisition capability, and organizational performance, it became necessary to fit a theoretical explanation to substantiate a possible interaction.

According to the interaction perception, the effect that a predictor variable (knowledge acquisition capability) has on an outcome variable (organizational performance) is contingent on the level of a third variable (strategic response capability), termed here as the mediator. The interactionist perspective explains a significant intervening mechanism (strategic response capability) between a criterion variable (knowledge acquisition capability) and the outcome variable (organizational performance). Specifically, the mediator variable accounts for a significant proportion of the relation between the predictor and criterion. In line with the interactionist perspective of fit-as-mediator, the study argues that given the relevance of knowledge acquisition capability and strategic response capability, the performance effect of the knowledge acquisition capability will be explained through the deployment of strategic response capability. This means that firms who possess the capability to acquire knowledge from the external environment that is critical to the firm's internal operations would enhance a firm's ability to respond to market dynamics and competitive intensity than those who do not. More so, if such a firm can effectively develop a strategic response capability, it would mediate the interaction between knowledge acquisition capability and organizational performance 
Onamusi, A. B.

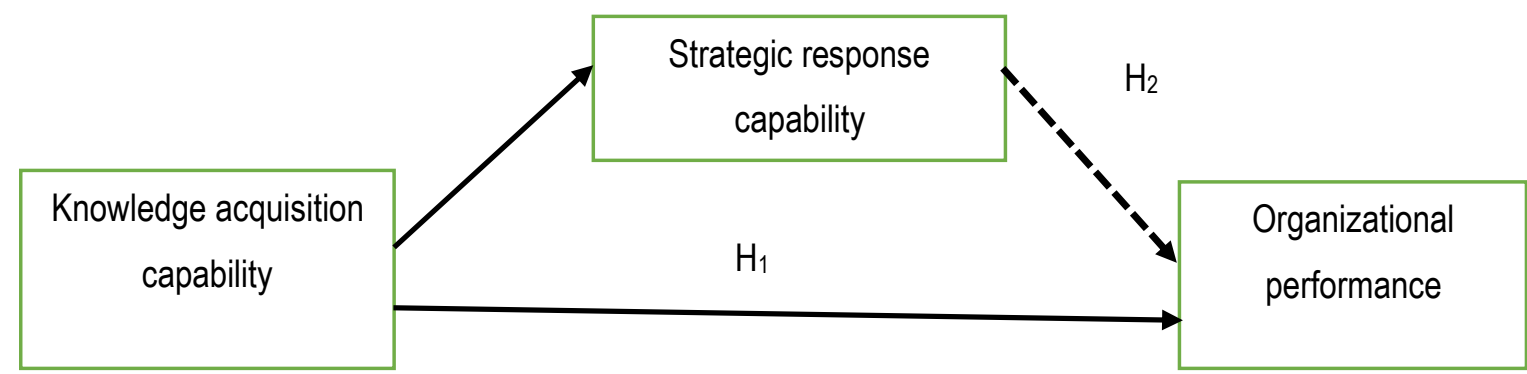

FIGURE. 1 CONCEPTUAL MODEL: KNOWLEDGE ACQUISITION CAPABILITY, STRATEGIC RESPONSE CAPABILITY, AND PERFORMANCE

Source: Researcher's Conceptual Model

\section{METHODOLOGY}

This study employed a cross-sectional survey design because it aids the collection of data at a point in time to verify the interaction between knowledge acquisition capability, strategic response capability, and organizational performance.

\subsection{The Study Context, Sampling and Data Collection}

The population of this study comprised of an infinite number of employees working with several organizations such as banks, small and medium enterprises, manufacturing companies in FMCGs, insurance companies, telecommunication firms, and the oil and gas in Oyo State, Nigeria. Using Crochan (1963) formula for calculation sample size from an infinite population, 384 was an appropriate sample size. To accommodate cases of anticipated non-response, $10 \%$ of the initial sample size was added to produce a sample size of 422 . The category of staff that made up the sample units were those in the top management level, middle management level, and the operational management level in the different organizations that have significant years of work experience.

The research instrument for data collection was a structured questionnaire considered relevant in collecting feedback based on the opinion of the respondents and it is suitable for collecting data within a short time on current issues. The items in the questionnaire were adapted. The adapted questionnaire was a standardized scale that has been used by authors on the subject matter of this research in another research context. The response options provided in this study's questionnaire followed the 6point Likert type scale ( 6 = strongly agree, $1=$ strongly disagree), consistent with (Binuyo et al., 2019). The administration and retrieval of the questionnaire took ten weeks. After the questionnaires were retrieved, they were screened to ensure that only properly filled questionnaires were collated for data analysis. In all 343 copies of questionnaire were considered usable representing $81.2 \%$ response rate. 


\subsection{Measurement of Variables}

Based on this study's conceptual model, the following dependent (organizational performance), independent (knowledge acquisition capability), and mediating (strategic response capability) variables were discussed taking cognizance of their measurement in extant literature.

\subsubsection{Dependent, Independent, and Moderating Variables}

Organizational Performance (OP)

Prior management studies measured organizational performance from the subjective point of view (through questionnaire item). Scholars argue that the subject view offers reliable data if objective (secondary data) are not readily obtainable. More so, authors have emphasized the use of both the financial and non-financial criteria to reflect the balance score-card approach to organizational performance. Specifically, scholars used performance measures such as; unique selling point, unique product offering, customer satisfaction, motivated workforce, sale revenue growth, and reaching financial goals, to define organizational performance.

Knowledge Acquisition Capability (KAC)

KAC measures the extent to which a firm can locate, identify, value, and acquire external knowledge that is critical to its operations (Chen et al., 2016; Kavusan et al., 2016). Avenues to acquire such knowledge include but not limited to; regularly visiting partners, collecting industry information through informal means (dinner), and periodically organizes special meetings with partners to acquire new knowledge. Also, having employees specialized in environmental scanning, and building relationships with regulatory authorities is another means through which firms can acquire knowledge.

\section{Strategic Response Capability (SRC)}

SRC measures the extent to which the firm can respond (either proactively or reactively) to events in its business environment that can influence its overall organizational performance (Muchiri et al., 2017; Imalingat, 2015). Extant literature considered two-dimensions which are internal response and external response capability as a way to comprehensively define strategic response capability (Arokodare et al., 2020; Muchiri et al., 2017). By measurement, SRC includes but not limited to; having a flexible business process, effective management resource planning, ability to collaborate with partners, ensuring quick changes to company policy, and possess competitor Knowledge. All the variables identified in this study were measured in concomitant with the measures discussed above. 


\subsection{Data Analysis}

The study employed simple regression analysis to establish the effect of knowledge acquisition capability on organizational performance as well as the functional relationship between strategic response capability and knowledge acquisition capability. Lastly, the study examined the indirect effect of strategic response capability on the relationship between knowledge acquisition capability and organizational performance using multiple (mediated) regression analysis.

\subsection{Model Specification}

$Y=f(X)$ $--1$

$Y=$ Dependent variable: Organizational Performance (OP)

$X=$ Independent variables: Knowledge Acquisition Capability (KAC)

$Z=$ Mediating variable: Strategic Response Capability (SRC)

To analyse mediation, this study followed Baron and Kenny's (1986) three steps identified below

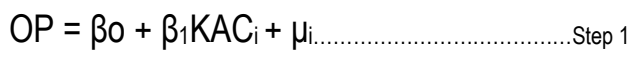

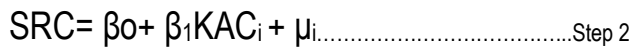

$\mathrm{OP}=\beta 0+\beta_{1} K A C_{i}+\beta_{2} R_{S C}+\mu_{i} \ldots \ldots \ldots \ldots \ldots$. Step 3

Where:

$\beta 0=$ the intercept expected value of $y$ when $x$ is equal to zero.

$\beta=$ the Coefficient of the independent variable (it is the rate of change in $y$ with respect to $x$ ).

$\mu=$ the error term to accommodate the effect of other variables that can influence organizational performance, but which were not included in the model.

\section{DATA ANALYSIS AND RESULT}

\subsection{Validity and Reliability Test}

The principal component analysis was conducted to ascertain the overall adequacy and validity of the instrument. A Kaiser-Meyer-Olkin (KMO) statistic greater than 0.73 confirmed the suitability of the items for factor analysis (Hair et al., 2017; Onamusi, 2020). The factor loadings of these items were used to establish the Average Variance Extracted (AVE). All the constructs have an AVE value above the threshold 0.5 . The construct, convergent validity and reliability result is presented in Table 1 below. 
Onamusi, A. B.

KNOWLEDGE ACQUISITION CAPABILITY, STRATEGIC RESPONSE CAPABILITY, AND ORGANIZATIONAL

PERFORMANCE: A MEDIATION ANALYSIS

TABLE 1. VALIDITY AND RELIABILITY TEST FOR MEASURED ITEMS

\begin{tabular}{lllll} 
Latent & Loadings CA & CR AVE \\
Variables & Items & & \\
\hline
\end{tabular}

Knowledge Regularly visiting partners to acquire new knowledge.

Acquisition Regularly collecting industry information through

Capability

informal means

0.73

$0.78 \quad 0.86$

0.60

Periodically organizes special meetings with partners

to acquire new knowledge.

0.81

Acquired new knowledge to fit the firm's development

needs.

Have people in the firm specialised in environmental 0.60

scanning

Build relationship with regulatory authorities

Regularly engaging direct marketing agencies

SRC:

Internal

Speedy collective decision

Response

Flexible business process

0.61

$0.82 \quad 0.86$

0.62

Management resource planning

0.78

Sensitive to opportunity

Quick changes to company policy

SRC:

externa

Possess competitor Knowledge

0.84

$0.82 \quad 0.84$

0.58

Response

Marketing scanning for opportunities

0.74

Explore new markets

0.57

Adapt to changing business environment

Organizational Motivated workforce

Performance Sale revenue growth

0.71

$0.89 \quad 0.83$

0.71

Acquire new market

Brand reputation

0.88

Reaching financial goals

0.88

Customer satisfaction 
Onamusi, A. B.

KNOWLEDGE ACQUISITION CAPABILITY, STRATEGIC RESPONSE CAPABILITY, AND ORGANIZATIONAL

PERFORMANCE: A MEDIATION ANALYSIS

TABLE 2. SUMMARY OF MULTIPLE REGRESSION ANALYSIS FOR THE MEDIATING EFFECT OF STRATEGIC RESPONSE ON THE INTERACTION BETWEEN KNOWLEDGE ACQUISITION CAPABILITY AND ORGANIZATIONAL PERFORMANCE

\begin{tabular}{|c|c|c|c|c|c|c|c|c|}
\hline Model & Beta & $t$ & Sig. & $\bar{R}$ & $\mathbf{R}^{2}$ & Adj. $R^{2}$ & $F(d f)$ & $\begin{array}{l}\text { ANOVA } \\
\text { Sig }\end{array}$ \\
\hline${ }^{1}$ (Constant) & 2.756 & 14.632 & 0.000 & 0.553 & 0.306 & 0.304 & $\begin{array}{l}150.057 \\
(1,341)\end{array}$ & 0.000 \\
\hline $\begin{array}{l}\text { Knowledge } \\
\text { Acquisition } \\
\text { capability }\end{array}$ & 0.489 & 12.250 & 0.000 & & & & & \\
\hline 2 (Constant) & 0.190 & 1.260 & 0.208 & 0.851 & 0.724 & 0.723 & $\begin{array}{l}894.757 \\
(1,341)\end{array}$ & 0.000 \\
\hline Strategic response & 0.925 & 29.912 & 0.000 & & & & & \\
\hline 3 (Constant) & 1.890 & 10.144 & 0.000 & 0.682 & 0.466 & 0.462 & $\begin{array}{l}148.135 \\
(2,340)\end{array}$ & 0.000 \\
\hline $\begin{array}{l}\text { Knowledge } \\
\text { Acquisition } \\
\text { capability }\end{array}$ & $\begin{array}{l}- \\
0.084\end{array}$ & -1.262 & 0.208 & & & & & \\
\hline Strategic response & 0.732 & 10.092 & 0.000 & & & & & \\
\hline
\end{tabular}

a. Predictors: (Constant), Knowledge Acquisition capability

b. Predictors: (Constant), Strategic Response

c. Predictors: (Constant), Knowledge Acquisition capability, Strategic Response

d. Dependent Variable: Organizational Performance

e. Note in Model 2 Knowledge Acquisition capability is the dependent variable in line with Baron and Kenny (1986)

Source: Author's computation using SPSS V23

In the first step (Model 1), the effect of knowledge acquisition capability on organizational performance was examined. In the Second step (Model 2), the effect of strategic response capability on knowledge acquisition capability was examined and in the third step (Model 3), the relative effect of knowledge acquisition capability and strategic response capability on organizational performance were examined and discussed in three paragraphs below.

More specifically, in the first step (Model 1), a simple regression analysis was conducted and the $\mathrm{R}^{2}$ was used as the determinant of the effect relationship. From the analysis, it was discovered that knowledge acquisition capability accounted for $30.6 \%$ of the variance recorded in organizational performance $\left(R^{2}=0.306, F(1,341)=150.057, p=0.000\right)$, while the remaining $69.4 \%$ is explained by extraneous variables not considered in this study. The ßeta coefficient of determination shows that a unit change in knowledge acquisition capability will increase organizational performance by 0.489 and 
the corresponding t-static and probability values showed the influence is statistically significant $(\beta=$ $0.489, t=12.250, p=0.000)$. The first precondition to conduct a mediation analysis suggests that the initial functional relationship between a predictor variable and an outcome variable must present a significant effect. This study as fulfilled this first precondition.

In the second step (Model 2), a simple regression analysis was conducted and from the analysis, it was discovered that strategic response capability accounted for $72.4 \%$ of the changes recorded in knowledge acquisition capability $\left(R^{2}=0.724, F(1,341)=894.757, p=0.000\right)$, while the remaining $27.6 \%$ is explained by extraneous variables not considered in this study. The ßeta coefficient of determination shows that a unit change in strategic response capability will result in 0.925 increase in knowledge acquisition capability and the corresponding t-static and probability values showed the influence is statistically significant $(\beta=0.925, t=29.912, p=0.000)$. The second precondition in the process of conducting a mediation analysis suggests that strategic response capability must have statistically significant effect on knowledge acquisition capability. This study as fulfilled this second precondition.

In the third step (Model 3), multiple regression analysis was conducted and the Adjusted $\mathrm{R}^{2}$ was employed as the determinant of the effect relationship given the presence of multiple predictor variables. The result revealed that knowledge acquisition capability and strategic response capability explained $46.2 \%$ variation experienced in organizational performance (Adj. $R^{2}=0.462, F(2,340)$ $=148.135 p=0.000$ ), while the remaining $53.8 \%$ is explained by variables not included in the regression model. The ßeta coefficient of determination shows that a unit change in knowledge acquisition capability will decrease organizational performance by -0.084 and the corresponding $t$-static and probability values showed the influence is insignificant $(\beta=-0.084, t=-1.262, p=0.208)$. However, the relative effect of strategic response capability shows that the Beta coefficient of determination shows that a unit change will increase organizational performance by 0.732 and the corresponding t-statistic and probability values showed the influence is significant $(\beta=0.732, t=10.092, p=0.000)$.

The third mediation precondition according to Baron and Kenny (1986), suggested that where a new predictor variable (strategic response capability) is introduced into the regression in model one changing it into a multiple regression model, the initial significant $\beta$ coefficient effect in model one become insignificant or disappears. If this assumption holds then a full mediation (indirect effect) effect is achieved. Hence, from the results in model 1, 2, and model 3, the study achieved the three preconditions for a mediate analysis, thus it establishes that strategic response capability fully mediate the interaction between knowledge acquisition capability and organizational performance and the indirect effect is positive and statistically significant. 


\section{DISCUSSION, CONCLUSION, AND RECOMMENDATION}

The study investigated the link between knowledge acquisition capability and organizational performance. Moreover, it examined the mediating effect of strategic response capability on the functional relationship between knowledge acquisition capability and organizational performance.

The findings align with the hypotheses formulated in this study hence providing important implications for theory and practice. The first hypothesis proposed that knowledge acquisition capability would positively influence organizational performance. This study shows that knowledge acquisition capability has a significant effect on organizational performance and this is consonance with past empirical studies (Forés and Camisón, 2016; Kavusan et al., 2016; Garcia- Martinez et al., 2018; Segarra-Ciprés and Bou-Llusar, 2018; Xie et al., 2018). This upheld the narrative that possessing the capability to acquire knowledge is a critical precondition for organizational performance found in extant literature (Arokodare, 2020; Muchiri et al., 2017).

The second hypothesis upholds the suppositions of both the dynamic capability and the contingency theory of fit-as-mediator. The dynamic capability promotes the ideology that firms desirous of achieving superior performance must develop and deploy unique internal and external competencies that is adaptable to a changing environment. All the predictor variables like knowledge acquisition capability and strategic response capability in this study are capabilities that are developed by firms and possess the attributes of changing to meet the demands of a changing environment. Also, by this study's result, the interactionist perspective of fit-as-mediator is strengthened in the sense that where the effectrelationship between two variables is explained by the introduction of a third variable (in this case strategic response capability) then the interactionist perspective of fit-as-mediator holds. This study strongly affirms this position with its result.

The contribution of this study to knowledge is in many ways. First, the study developed a conceptual model that expressed the effect of knowledge acquisition capability on organizational performance. The model equally showed the mediating effect of strategic response capability on the established effect of knowledge acquisition capability on organizational performance. Third, the empirical results add to current literature on firm-level capabilities which showed that the interaction term of knowledge acquisition capability and strategic response capability significantly mediate the interaction between knowledge acquisition capability and organizational performance. Lastly, this study further corroborates the position of the dynamic capability theory and the interactionist perspective, hence, providing additional support for the assumptions of both theories.

The study concluded that knowledge acquisition capability benefits organizations' performance through the deployment of strategic response capability. Hence, this study recommends that firms should 
strengthen their competency to develop innovative means of acquiring knowledge either from within or outside the organization, more so they should develop highly creative means to respond to both competitive rivalry and environmental challenges. This is because both capabilities can be adopted as competitive strategies in responding to the changing environment and achieving significant superior performance.

\section{REFERENCES}

Akinyele, T., \& Fasogbon, I. (2010). Impact of strategic responses on firm performance and survival in Nigeria. Research Journal of Business Management, 4(1): 73-82.

Arokodare, A. (2020). Strategic agility: Achieving superior organizational performance through strategic foresight. Global Journal of Management and Business Research. 20(3): 7-16.

Baron, R. M., \& Kenny, D. A. (1986). The moderator-mediator variable distinction in social psychological research: Conceptual, strategic, and statistical considerations. Joumal of Personality and Social Psychology, 51(6): 1173-1182.

Binuyo, A. O., Ekpe, H., \& Binuyo, B. O. (2019). Innovative strategies and firm growth: evidence from selected fast moving consumer goods firms in Lagos state, Nigeria. Problems and Perspectives in Management, 17(2): 313.

Chen, P., Tan, D., \& Jean, R. (2016). Foreign knowledge acquisition through inter-firm collaboration and recruitment: Implications for domestic growth of emerging market firms. International Business Review, 25(1): 221-232.

Chukwuemeka, O. W., \& Onuoha, B. C. (2018). Dynamic capabilities and competitive advantage of fast foods restaurants. International Journal of Management Science and Business Administration, 4(3): 7-14.

Collins, R. (2014). Strategic responses by manufacturing firms in the Netherlands, (PDF), Retrieved 26 April, 2016.

Cochran, W. G. 1963. Sampling Techniques, 2nd Ed., New York: John Wiley and Sons, Inc

Feng, T., Huang, Y., \& Avgerinos, E. (2018). When marketing and manufacturing departments integrate: The influences of market newness and competitive intensity. Industrial Marketing Management, 75(9), 218-231.

Fidel, P., Schlesinger, W., \& Cervera, A. (2015). Collaborating to innovate: Effects on customer knowledge management and performance. Joumal of Business Research, 68(7): 14261428.

Forés, B., \& Camisón, C. (2016). Does incremental and radical innovation performance depend on different types of knowledge accumulation capabilities and organizational size? Journal of Business Research, 69(2): 831-848.

Frankort, H. T. (2016). When does knowledge acquisition in R\&D alliances increase new product development? The moderating roles of technological relatedness and product-market competition. Research Policy, 45(1): 291-302.

Garcia Martinez, M., Zouaghi, F., Garcia Marco, T., \& Robinson, C. (2018). What drives business failure? Exploring the role of internal and external knowledge capabilities during the global financial crisis. Journal of Business Research. doi:10.1016/j.jbusres.2018.07.032

Grant, A. (1996). Marketing: The need to contribute to overall business effectiveness. Journal of Marketing Practice: Applied Marketing Science, 2(3): 7-11.

Hair, J.F., Hult, G.T.M., Ringle, C.M., \& Sarstedt, M. (2017). A primer on partial least squares structural equation modeling (PLS-SEM), 2nd ed. Thousand Oaks, CA: Sage. 
Imalingat, S. (2015). Strategic responses of mobile money transfer service in Barclays bank in Kampala, Uganda, Published Master Thesis, Bugema University.

Kaur, V., \& Mehta, V. (2016a). Knowledge-based dynamic capabilities: A new perspective for achieving global competitiveness in IT sector. Pacific Business Review International, 1(3): 96-106.

Kavusan, K., Noorderhaven, N. G., \& Duysters, G. M. (2016). Knowledge acquisition and complementary specialization in alliances: The impact of technological overlap and alliance experience. Research Policy, 45(10): 2153-2165.

Ketchen, D., \& Palmer, T. (2013). Strategic responses to poor organizational performance: A test of competing perspectives, Psychology Management, 4,185

Kimunguyi, E. S. (2013). Response strategies adopted by agrochemical companies to the challenges of agrochemical distribution in Kenya, published MBA Project, University of Nairobi

Lee, P., Wu, M., Kuo, C., \& Li, C.J. (2016). How to deploy multiunit organizations' dynamic capabilities? Management Decision, 54(4): 965-980.

Liao, Y., \& Marsillac, E. (2015). External knowledge acquisition and innovation: The role of supply chain network-oriented flexibility and organizational awareness. International Journal of Production Research, 53(18): 5437-5455.

McCann, B. T., \& Bahl, M. (2016). The influence of competition from informal firms on new product development. Strategic Management Journal, 38(7): 1518-1535.

Mu, J., Bao, Y., Sekhon, T., Qi, J., \& Love, E. (2018). Outside-in marketing capability and firm performance. Industrial Marketing Management, 75(6): 37-54.

Mu, J. (2015). Marketing capability, organizational adaptation and new product development performance. Industrial Marketing Management, 49(7): 151-166.

Muchiri, L., Ombui, K., \& Iravo, M. A. (2017). Impact of strategic responses on the performance of oil marketing companies in Kenya. International Journal of Scientific and Research Publications, 7(10).

Najafi-Tavani, S., Najafi-Tavani, Z., Naudé, P., Oghazi, P., \& Zeynaloo, E. (2018). How collaborative innovation networks affect new product performance: Product innovation capability, process innovation capability, and absorptive capacity. Industrial Marketing Management, 73(4): 193205.

Onamusi, A.B. (2020). Entry mode strategy, customer engagement and firm performance. Journal of Business and Social Review in Emerging Economies, 6(1): 99-112.

Segarra-Ciprés, M., \& Bou-Llusar, J. C. (2018). External knowledge search for innovation: The role of firms' innovation strategy and industry context. Journal of Knowledge Management, 22(2): 280-298.

Segarra-Ciprés, M., Roca-Puig, V., \& Bou-Llusar, J. C. (2014). External knowledge acquisition and innovation output: An analysis of the moderating effect of internal knowledge transfer. Knowledge Management Research \& Practice, 12(2): 203-214.

Szulanski, G., Ringov, D., \& Jensen, R. J. (2016). Overcoming stickiness: How the timing of knowledge transfer methods affects transfer difficulty. Organization Science, 27(2): 304-322.

Vanpoucke, E., Vereecke, A., \& Wetzels, M. (2014). Developing supplier integration capabilities for sustainable competitive advantage: A dynamic capabilities approach. Journal of Operations Management, 32(7-8): 446-461.

Xie, X., Wang, L., \& Zeng, S. (2018). Inter-organizational knowledge acquisition and firms' radical innovation: A moderated mediation analysis. Journal of Business Research, 90(3): 295-306.

Zhang, M., \& Hartley, J. L. (2018). Guanxi, IT systems, and innovation capability: The moderating role of proactiveness. Journal of Business Research, 90(5): 75-86. 